\title{
Tidal changes in respiratory resistance are sensitive indicators of airway obstruction in children
}

\author{
Dorottya Czövek, ${ }^{1,2}$ Claire Shackleton, ${ }^{1,2}$ Zoltán Hantos, ${ }^{1,2,3,4}$ Kate Taylor, ${ }^{1}$ \\ Anushma Kumar, ${ }^{1}$ Archana Chacko, ${ }^{1}$ Robert S Ware, ${ }^{2}$ Gergely Makan, ${ }^{5}$ \\ Bence Radics, ${ }^{4}$ Zoltán Gingl, ${ }^{5}$ Peter D Sly ${ }^{1,2}$
}

\begin{abstract}
- Additional material is published online only. To view please visit the journal online (http://dx.doi.org/10.1136/ thoraxjnl-2015-208182).
\end{abstract}

For numbered affiliations see end of article.

\section{Correspondence to}

Dr Dorottya Czovek, Level 7, Centre for Children's Health Research, 62 Graham street, South Brisbane, QLD 4101, Australia; d.czovek@uq.edu.au

$\overline{D C}$ and CS contributed equally.

Received 10 December 2015 Revised 24 February 2016 Accepted 17 April 2016 Published Online First 13 May 2016
CrossMark

To cite: Czövek D,
Shackleton C, Hantos Z,
et al. Thorax 2016;71:907-
915.

\section{ABSTRACT}

Rationale Individual assessment of airway obstruction in preschool-age children requires sensitive and specific lung function methods with low demand of cooperation. Although the forced oscillation technique (FOT) is feasible in young children, conventional measurements of respiratory impedance (Zrs) have limited diagnostic power in individuals.

Objective To find descriptors of within-breath Zrs that are sensitive indicators of airway obstruction during tidal breathing in children.

Methods Zrs was measured with (i) a standard multifrequency FOT (4-26 Hz) to assess the mean values of resistance and reactance for whole breaths and (ii) a $10 \mathrm{~Hz}$ signal to track the within-breath changes. Various Zrs measures obtained in healthy children $(n=75)$ and those with acute wheeze $(n=31)$ were investigated with receiver operator characteristic (ROC) analysis. The cut-off values obtained for airway obstruction were then tested in children with recurrent wheeze $(n=20)$ before and after administration of salbutamol.

Results The largest area under the ROC curve (0.95) was observed for the tidal changes of resistance between the zero-flow values $(\Delta R)$. The $\Delta R$ cut-off value of $1.42 \mathrm{hPa}$ s/L detected airway obstruction with sensitivity of $92 \%$ and specificity of $89 \%$ in children with acute wheeze and distinguished children with recurrent wheeze (16/20 above the cut-off value) from healthy children (22/23 below the cut-off value). Furthermore, $\Delta R$ significantly decreased after salbutamol in wheezy children but remained unchanged in healthy children.

Conclusions New lung function measure $\Delta R$ is able to detect airway obstruction with high sensitivity and specificity and is suitable for use in lung function testing in young children.

\section{INTRODUCTION}

Detection of acute pulmonary dysfunction in young children remains a challenge for physicians as there is no lung function method available in the routine clinical care that can be performed easily and reliably in sick young children. ${ }^{1-3}$ This is particularly important considering that more than half the children hospitalised for wheeze or asthma exacerbation are below 6 years of age. ${ }^{4}$ Spirometry, the 'gold standard' lung function test, has many limitations in preschool-age children, especially when they are unwell. In addition to the high cooperation required

\section{Key messages}

What is the key question?

- Can airway obstruction be detected in individual preschool-aged children with wheeze?

\section{What is the bottom line?}

- Unlike previous lung function techniques that are able to detect differences between groups of children our novel method detects airway obstruction in individual children with sensitivity of $92 \%$ and specificity of $89 \%$.

\section{Why read on?}

- Measuring the volume dependence of resistance during tidal breathing using a modification of the forced oscillation technique has the potential to change the way asthma and other respiratory diseases are assessed in young children.

for the respiratory manoeuvres, the technique is not applied consistently in children below 6 years of age, as different outcome measures and cut-off points have been suggested for the assessment of airway obstruction. ${ }^{13}{ }^{5-7}$ Alternative lung function methods have been developed in recent decades to overcome these problems; however, these techniques are more frequently employed in research studies assessing differences in lung function between healthy and diseased study groups, and are not routinely used in clinical practice. ${ }^{13}$ Objective measurements of lung function validated for detecting abnormalities in individual young children would present a significant advance.

The forced oscillation technique (FOT) has been employed widely in paediatric lung function testing due to its non-invasive nature and the lack of special breathing manoeuvres required from the subject. Several reports have addressed the utility of the FOT in paediatrics, ${ }^{1} 389$ and normative data are available; ${ }^{10-13}$ however, FOT methodology and data interpretation differ between commercial devices. ${ }^{1}$ In addition, current opinion suggests that FOT is more useful for showing differences between groups rather than following disease in individuals. ${ }^{1}{ }^{3}$ This may, in part be due to the large variance of normal data in preschool-age children. $^{10-13}$ 
Respiratory impedance ( $\mathrm{Zrs}$ ) is commonly determined at multiple oscillation frequencies and averaged over several breaths ${ }^{8} 1415$ with the tacit assumption of linearity, that is, that the mechanical properties of the respiratory system do not change during quiet breathing. However, there is strong evidence that non-linear phenomena (flow and volume dependence of impedance) result in marked within-breath changes in respiratory resistance (R). ${ }^{16-19}$ Although the effect of the upper airways on $\mathrm{R}$ has not been fully established, previous research on the upper airway and vocal cord physiology demonstrated that the area of the glottic aperture achieved a minimum value in midexpiration and thus elevates the mean $\mathrm{R}$ during expiration. This effect was greater in the presence of airway obstruction. ${ }^{2021}$ An important message from these studies was that the effects of flow and the geometry of the upper airways on $\mathrm{R}$ were significant in both health and disease, even during quiet breathing, and that the mean $\mathrm{R}$ values from total breaths or from whole inspiratory and expiratory phases separately are fundamentally dependent on the flow pattern.

The present study aimed to examine within-breath changes in $\mathrm{Zrs}$, in order to determine $\mathrm{R}$ in phases of the breathing cycle that are the least affected by the breathing pattern (ie, airflow) and the rheology of the upper airways. We hypothesised that the change in $\mathrm{R}$ with tidal volume (measured between the zeroflow points at end-expiration and end-inspiration) would be a sensitive indicator of airway calibre and hence the airway obstruction during tidal breathing in wheezy preschool-age children.

\section{METHODS}

\section{Subjects and study procedures}

Children with acute wheeze (study I)

Preschool-age children admitted with acute wheeze to the Emergency Department of the Royal Children's Hospital, Brisbane, Australia were enrolled in the study between June 2014 and August 2015. The relevant clinical information is shown in table 1 . Children were eligible to participate if they (1) had detectable wheeze on auscultation; (2) needed treatment with short-acting $\beta 2$ receptor agonist (SABA) and (3) did not require supplemental oxygen by the time of the lung function measurement. Lung function from children who had SABA $1 \mathrm{~h}$

Table 1 Clinical symptoms and treatment of wheezy children from studies I and II

\begin{tabular}{lcc}
\hline Clinical symptoms & $\begin{array}{l}\text { Acute wheeze } \\
(\mathbf{n}=\mathbf{2 6})\end{array}$ & $\begin{array}{l}\text { Recurrent wheeze } \\
(\mathbf{n}=\mathbf{2 0})\end{array}$ \\
\hline Doctor diagnosis of asthma & 9 & 7 \\
$\geq 1$ hospital admission* & 12 & 6 \\
No wheezy episode* $^{*}$ & 2 & 2 \\
1-3 wheezy episodes* & 14 & 11 \\
$4-12$ wheezy episodes* & 7 & 7 \\
$>12$ wheezy episodes* & 3 & 0 \\
Medicationt & & 4 \\
$\quad$ Daily treatment with ICS $( \pm$ LTRA) & 8 & 3 \\
Daily treatment with LTRA only & 0 & 4 \\
SABA only (pro re nata) & 13 & 9 \\
No treatment & 5 & \\
\hline
\end{tabular}

* In the 12 months prior to the study visit.

†Medication use prior to the study visit.

ICS, inhaled corticosteroids; LTRA, leukotriene receptor antagonist; SABA, short-acting $\beta 2$-agonist. prior to the study visit was excluded from the analysis. Parents completed a modified International Study of Asthma and Allergies in Childhood (ISAAC) questionnaire (see online supplementary appendix) for their child, and lung function was then measured. Another group of children $(n=75)$ was recruited from local kindergartens as healthy controls. The consent form and a questionnaire regarding the respiratory status of their child were mailed to the parents and the forms were collected on the day of the visit. Children were defined as healthy based on the following criteria assessed in the questionnaire: (1) $\geq 37$ completed weeks of gestation, (2) no prior diagnosis of asthma or other respiratory disease or known growth defects and (3) asymptomatic at least for 4 weeks prior to testing.

\section{Children with recurrent wheeze (study II)}

Children with stable wheeze or asthma (ie, more than three wheezy episodes after the first year of life and/or doctor diagnosis of asthma, table 1; symptom-free for at least 4 weeks prior to the study visit, $n=20$ ) were recruited from Asthma Clinics at the Royal Children's Hospital, Brisbane between April and November 2015. Informed consent was obtained and lung function measured before and after the administration of $400 \mu \mathrm{g}$ inhaled salbutamol (Ventolin, GlaxoSmithKline, Ermington, New South Wales, Australia) via a spacer (Aerochamber, Trudell Medical International, London, Ontario, Canada). Bronchodilator response was also assessed in a subgroup of the healthy children $(n=23)$.

Both studies were approved by the Children's Health Services Human Research Ethics Committee, Brisbane, Australia.

\section{Impedance measurements}

Custom-made FOT equipment, consisting of a loudspeaker and a wave tube was used to measure Zrs. ${ }^{22} \mathrm{~A}$ pneumotachograph was employed to record changes in flow and volume during tidal breathing (figure 1). Two types of FOT measurements were performed in each subject during tidal breathing. First, Zrs was measured with a multiple-frequency pseudorandom signal between 4 and $26 \mathrm{~Hz}$ for $16 \mathrm{~s}$; these measurements were repeated until three reproducible Zrs spectra were obtained and these spectra were ensemble averaged. Second, the within-breath changes in Zrs were tracked with a single $10 \mathrm{~Hz}$ sinusoid, and all regular breathing periods from three recordings were selected for analysis. Details of the Zrs measurements are given in the online supplementary appendix.

\section{Data analysis}

Mean values of $\mathrm{R}$ and $\mathrm{X}$ at each measured frequency were determined from the averaged Zrs spectra and those at 6,8 and

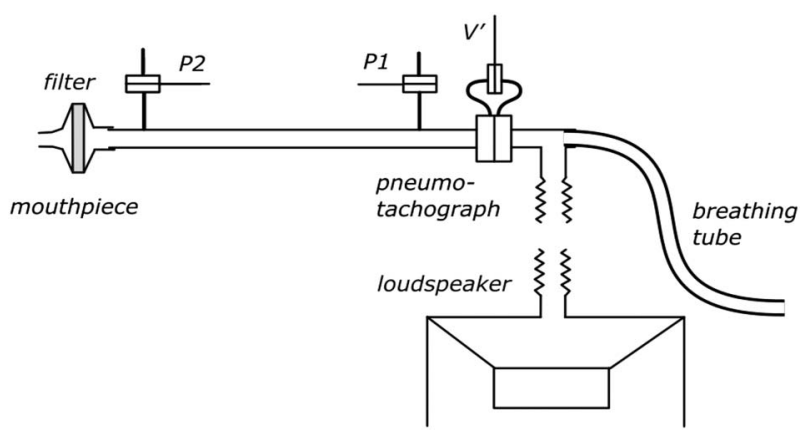

Figure 1 Forced oscillation technique device. P1 and P2 are two identical pressure transducers to measure the inlet and outlet pressures of the wave tube. 
$10 \mathrm{~Hz}\left(\mathrm{R}_{6}, \mathrm{R}_{8}, \mathrm{R}_{10}, \mathrm{X}_{6}, \mathrm{X}_{8}\right.$ and $\left.\mathrm{X}_{10}\right)$ are reported. From the temporal recordings, $\mathrm{R}$ and $\mathrm{X}$ were obtained at every $0.1 \mathrm{~s}$ from all the artefact-free breathing cycles and their values were calculated at specific time points (figure 2 and table 2). The temporal variables are summarised in table 2 . Tidal volume $\left(\mathrm{V}_{\mathrm{T}}\right)$, tidal inspiratory $\left(\mathrm{V}_{\text {max }}^{\prime}\right)$ and expiratory flows $\left(\mathrm{V}_{\text {maxE }}^{\prime}\right)$, breathing frequency $\left(\mathrm{F}_{\mathrm{br}}\right)$ and the expiratory time relative to the total breathing period $\left(\mathrm{T}_{\mathrm{E}} / \mathrm{T}_{\text {tot }}\right)$ were obtained from the tidal flow signal.

\section{Statistical analysis}

Summary statistics for continuous variables are presented as either mean \pm SD or median (25\% percentile; $75 \%$ percentile) as appropriate. The differences in Zrs and tidal breathing variables between the groups in study I were assessed with the Wilcoxon rank sum tests. A $p$ value of $<0.05$ was considered statistically significant. The sensitivity and specificity, negative and positive predicted values (NPV and PPV, respectively) and likelihood ratios of the variables to detect airway obstruction were determined using receiver operator characteristic (ROC) analysis. Cut-off value for each of the variables was defined as the best relationship between sensitivity and specificity. The effect of salbutamol was analysed using the two-way repeated measures of analysis of variance.

\section{RESULTS}

\section{Children with acute wheeze (study I)}

Three obstructed children who received SABA $<1 \mathrm{~h}$ prior to the FOT measurements were excluded from the analysis while two children were not able to perform lung function testing (figure 3). The demographic characteristics of the children in the two groups are summarised in table 3 .

\section{Respiratory function}

Zrs data collected with the pseudorandom signal are shown in figure 4. The conventional FOT variables $\left(\mathrm{R}_{6}, \mathrm{R}_{8}, \mathrm{R}_{10}, \mathrm{X}_{6}, \mathrm{X}_{8}\right.$

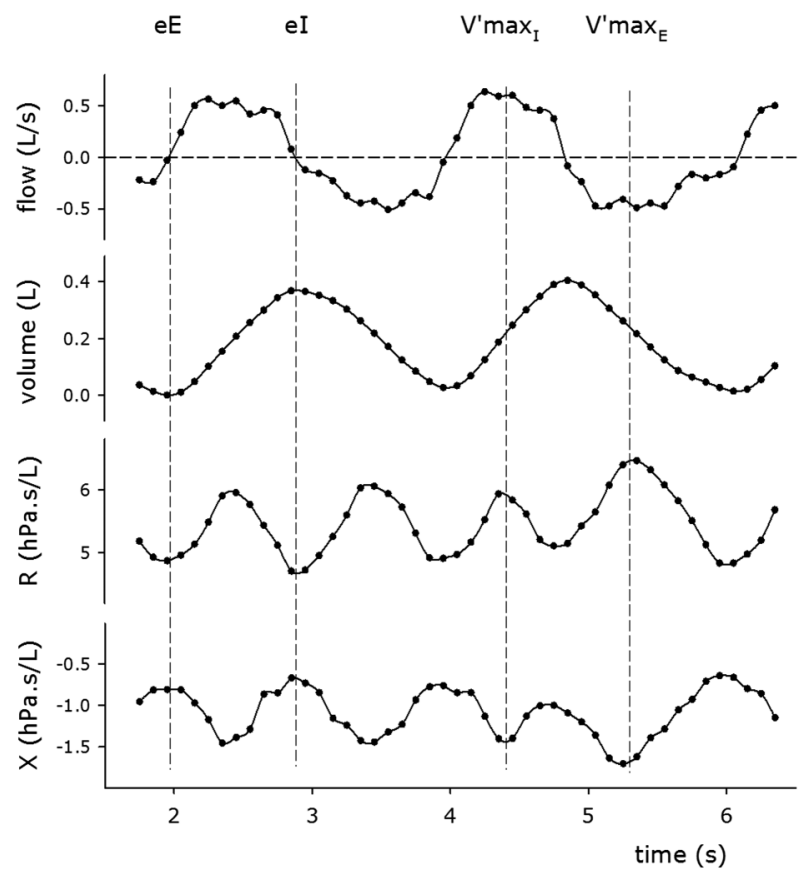

Figure 2 Tidal changes in resistance $(R)$ and reactance $(X)$ with the flow and volume traces. Dashed lines indicate time points of end-expiration (eE), end-inspiration (el), maximum inspiratory flow $\left(\mathrm{V}_{\text {maxl }}^{\prime}\right)$ and maximum expiratory flow $\left(\mathrm{V}_{\text {max }}^{\prime}\right)$. and $\mathrm{X}_{10}$ ) did not differ between the two groups $(\mathrm{p}=0.54,0.88$, $0.60,0.72,0.16$ and 0.37 , respectively). The expiration was proportionally longer and $\mathrm{V}^{\prime}{ }_{\max }$ was reduced in children with acute airway obstruction (table 3); however, minute ventilation was similar in the two groups $(p=0.42)$. The mean values of $R$ during inspiration $\left(\mathrm{R}_{\text {meanI }}\right)$ and expiration $\left(\mathrm{R}_{\text {meanE }}\right)$ did not distinguish between the two groups whereas the inspiratory and expiratory mean reactance $\left(\mathrm{X}_{\text {meanI }}\right.$ and $\mathrm{X}_{\text {meanE}}$, respectively) were significantly lower in children with acute airway obstruction. The differences between the corresponding inspiratory and expiratory mean values $\left(\Delta \mathrm{R}_{\text {mean }}\right.$ and $\left.\Delta \mathrm{X}_{\text {mean }}\right)$ did not differ between the groups (table 4 ).

The changes in the group mean values of $\mathrm{R}$ and $\mathrm{X}$ during tidal breathing are illustrated in figure 5. At the end of expiration, $\mathrm{R}$ was significantly higher in children with acute airway obstruction compared with healthy subjects $(\mathrm{p}<0.001)$ and remained elevated at $\mathrm{V}_{\max }^{\prime}(\mathrm{p}=0.007)$. By the end of inspiration, $\mathrm{R}$ decreased, with the difference in $\mathrm{R}$ between the groups disappearing $(p=0.51)$. The onset of expiratory flow resulted in a fast rise in $\mathrm{R}$ in both groups; however, in children with acute airway obstruction $R$ was higher $(p=0.02)$ and remained elevated at the end of expiration. The changes in $\mathrm{X}$ during tidal breathing mirrored the changes in $\mathrm{R}$, with statistically significant differences between the two groups at end-expiration $(\mathrm{p}<0.001)$, at $\mathrm{V}_{\operatorname{maxI}}^{\prime}(\mathrm{p}<0.001)$ and $\mathrm{V}_{\operatorname{maxE}}^{\prime}(\mathrm{p}=0.005)$.

The most significant differences between the two groups were the changes in $\mathrm{R}$ and $\mathrm{X}$ between the beginning and the end of inspiration, as illustrated by typical $\mathrm{R}$ and $\mathrm{X}$ versus volume and flow loops in figure 6. Children with acute airway obstruction exhibited a significantly increased difference in $R$ between end-expiration and end-inspiration $(\Delta \mathrm{R}$, figure $6 \mathrm{~B})$ compared with healthy children (figure $6 \mathrm{~A} ; 2.42 \pm 1.31$ vs 0.61 $\pm 0.66 \mathrm{hPa} \mathrm{s} / \mathrm{L}, \mathrm{p}<0.001)$, and this difference remained unchanged when $\Delta \mathrm{R}$ was corrected for $\mathrm{V}_{\mathrm{T}}(7.73 \pm 5.83$ vs 1.87 $\left.\pm 2.63 \mathrm{hPa} \mathrm{s} / \mathrm{L}^{2}, \mathrm{p}<0.001\right)$. Furthermore, $\Delta \mathrm{R}$ exhibited no relationship with the height-corrected tidal volume $\left(\mathrm{cV}_{\mathrm{T}} ; \mathrm{r}^{2}=0.02\right.$, $\mathrm{p}=0.25$ ) while both $\mathrm{R}_{\mathrm{eE}}$ and $\mathrm{R}_{\mathrm{eI}}$ were negatively related to $\mathrm{cV}_{\mathrm{T}}$ $\left(\mathrm{r}^{2}=0.06\right.$ and $\mathrm{r}^{2}=0.42$, respectively, both $\left.\mathrm{p}<0.001\right)$. There was a weak (although statistically significant) relationship between $\mathrm{T}_{\mathrm{E}} / \mathrm{T}_{\text {tot }}$ and $\Delta \mathrm{R}\left(\mathrm{r}^{2}=0.06, \mathrm{p}=0.013\right)$; however, when height was included as a covariable in the regression, the significance disappeared $(p=0.055)$. We note here that there was no relationship between $V_{T}, T_{E} / T_{\text {tot }}$ and the conventional measures of respiratory resistance and reactance, that is, mean $\mathrm{R}$ and $\mathrm{X}$ at different frequencies (data not shown). The tidal change in $X(\Delta X)$ was similar in magnitude in the two groups but opposite in sign $(0.29 \pm 1.08$ vs $-0.40 \pm 0.54 \mathrm{hPa}$ s $/ \mathrm{L}, \mathrm{p}<0.001)$.

Table 2 Definitions of the within-breath impedance measures obtained from the $10 \mathrm{~Hz}$ recordings

\begin{tabular}{lll}
\hline Phases of the breathing cycle & Resistance (R) & Reactance (X) \\
\hline Whole expiration (meanE) & $\mathrm{R}_{\text {meanE }}$ & $\mathrm{X}_{\text {meanE }}$ \\
Whole inspiration (meanl) & $\mathrm{R}_{\text {meanl }}$ & $\mathrm{X}_{\text {meanl }}$ \\
Difference between meanE and meanl & $\Delta \mathrm{R}_{\text {mean }}$ & $\Delta \mathrm{X}_{\text {mean }}$ \\
End-expiration (eE) & $\mathrm{R}_{\mathrm{eE}}$ & $\mathrm{X}_{\mathrm{eE}}$ \\
End-inspiration (el) & $\mathrm{R}_{\mathrm{el}}$ & $\mathrm{X}_{\mathrm{el}}$ \\
Difference between eE and el & $\Delta \mathrm{R}$ & $\Delta \mathrm{X}$ \\
Maximum expiratory flow (maxE) & $\mathrm{R}_{\mathrm{V}^{\prime} \text { maxE }}$ & $\mathrm{X}_{\mathrm{V}^{\prime} \text { maxE }}$ \\
Maximum inspiratory flow (maxl) & $\mathrm{R}_{\mathrm{V}^{\prime} \text { maxl }}$ & $\mathrm{X}_{\mathrm{V}^{\prime} \text { maxl }}$ \\
Area within the resistance versus flow loops & $\mathrm{ARV}^{\prime}$ & - \\
\hline
\end{tabular}




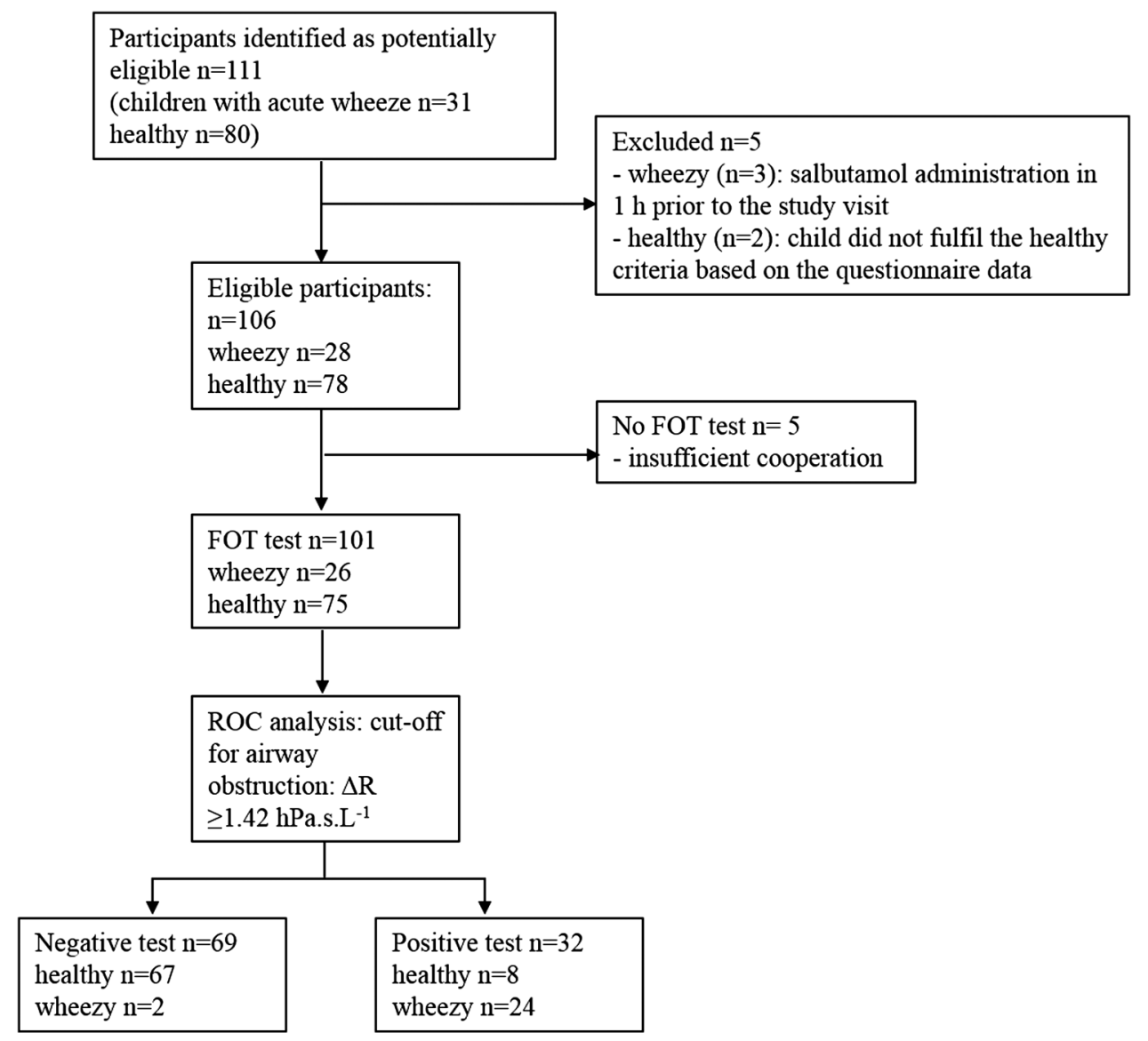

Figure 3 Flow chart of participants in study I. FOT, forced oscillation technique; ROC, receiver operator characteristic.

Diagnostic value of impedance measures for detecting airway obstruction

The ROC curves for $\mathrm{R}_{\text {meanE }}, \mathrm{R}_{\text {meanI }}, \mathrm{X}_{\text {meanE }}, \mathrm{X}_{\text {meant }}, \Delta \mathrm{R}$ and $\Delta \mathrm{X}$ are presented in figure 7 . The largest area under the curve (AUC) was observed for $\Delta \mathrm{R}(0.95)$ and $\Delta \mathrm{X}(0.79)$, corresponding to higher values of sensitivity and specificity to detect airway obstruction than that of the mean inspiratory or mean expiratory $\mathrm{Zrs}$ variables $\left(\mathrm{R}_{\text {meanE }}: 0.60 ; \mathrm{R}_{\text {mean }}: 0.60 ; \mathrm{X}_{\text {meanE }}\right.$ : 0.65 and $\mathrm{X}_{\text {meanI }}: 0.70$; all $\mathrm{p}<0.0001$ vs $\left.\Delta \mathrm{R}\right)$. Optimal detection of airway obstruction was established with a $\Delta \mathrm{R}$ of $\geq 1.42 \mathrm{hPa}$ $\mathrm{s} / \mathrm{L}$, which corresponded to a sensitivity of $95 \%(75-99)$ and a specificity of $89 \%$ (80-95) with NPV and PPV of 97\% (90-99)

\begin{tabular}{|c|c|c|c|}
\hline & Healthy $(n=75)$ & Acute wheeze $(n=26)$ & $\mathrm{p}$ Value \\
\hline Age (year) & $4.8(4.3 ; 5.2)$ & $4.8(3.9 ; 6.0)$ & 0.93 \\
\hline Height (cm) & $108.3(105.9 ; 116.9)$ & $110.6(102.1 ; 118.5)$ & 0.24 \\
\hline Weight (kg) & $19.0(16.2 ; 21.1)$ & $20.7(17.7 ; 23.6)$ & 0.46 \\
\hline Tidal volume $(\mathrm{mL})$ & $289(232 ; 378)$ & $337(270 ; 428)$ & 0.15 \\
\hline $\mathrm{F}_{\mathrm{br}}$ (breath/min) & $28(23 ; 32)$ & $26(22 ; 34)$ & 0.30 \\
\hline $\mathrm{T}_{\mathrm{E}} / \mathrm{T}_{\text {tot }}$ & $0.54(0.52 ; 0.57)$ & $0.57(0.55 ; 0.59)$ & $0.002^{*}$ \\
\hline$V^{\prime} \max _{\mathrm{E}} / V^{\prime} \max _{1}$ & $0.88(0.81 ; 0.97)$ & $0.81(0.72 ; 0.92)$ & $0.014^{*}$ \\
\hline
\end{tabular}

and 75 (57-89), respectively, calculated for the prevalence of wheeze in the study population $(25.7 \% ; 26 / 101$ children). This prevalence is comparable with the expected proportion of preschool-age children with recurrent wheeze who go on to develop persistent asthma (30\%). The cut-off values for potential outcome measures with values of sensitivity and specificity, NPV, PPV, positive and negative likelihood ratios are shown in the online supplementary appendix.

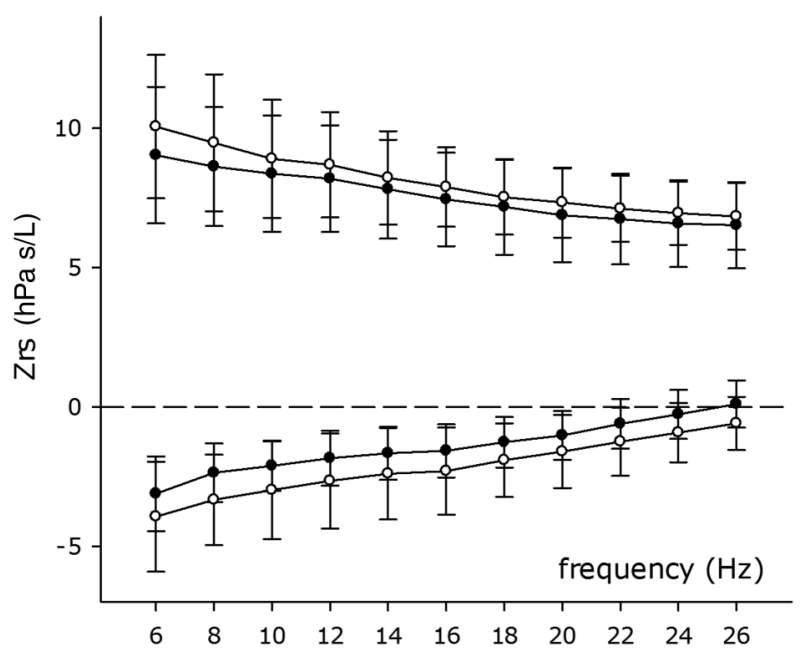

Figure 4 Impedance (Zrs) spectra between 6 and $26 \mathrm{~Hz}$ obtained in children with acute wheeze (open circles) and that in healthy subjects (closed circles). Bars represent SD. 
Table 4 Impedance measures calculated for expiration $\left(R_{\text {meanE, }}\right.$ $\left.X_{\text {meanE }}\right)$ and inspiration $\left(R_{\text {meanl }}, X_{\text {meanl }}\right)$ and their differences $\left(\Delta R_{\text {mean }}, \Delta X_{\text {mean }}\right)$ in the two groups of children (study $\left.\mathrm{I}\right)$

\begin{tabular}{lccl}
\hline $\begin{array}{l}\text { Impedance } \\
\text { measures } \\
(\mathrm{hPa} \text { s/L) }\end{array}$ & Healthy $(\mathrm{n}=75)$ & $\begin{array}{l}\text { Acute wheeze } \\
(\mathrm{n}=26)\end{array}$ & $\mathrm{p}$ Value \\
\hline $\mathrm{R}_{\text {meanE }}$ & $8.63(7.48 ; 10.13)$ & $9.23(7.82 ; 10.90)$ & 0.12 \\
$\mathrm{R}_{\text {meanl }}$ & $7.74(6.73 ; 8.66)$ & $8.26(7.17 ; 9.25)$ & 0.14 \\
$\Delta \mathrm{R}_{\text {mean }}$ & $0.97(0.60 ; 1.41)$ & $1.14(0.36 ; 1.83)$ & 0.30 \\
$\mathrm{X}_{\text {meanE }}$ & $-1.83(-2.96 ;-1.16)$ & $-2.70(-4.17 ;-1.70)$ & $0.026^{*}$ \\
$\mathrm{X}_{\text {meanl }}$ & $-1.75(-2.41 ;-1.01)$ & $-2.22(-3.24 ;-1.81)$ & $0.014^{*}$ \\
$\Delta \mathrm{X}_{\text {mean }}$ & $-0.19(-0.50 ; 0.29)$ & $0.05(-0.67 ; 0.29)$ & 0.66 \\
\hline
\end{tabular}

Data are presented as median (25th percentile; 75 th percentile).

*Statistically significant difference.

\section{Children with recurrent wheeze (study II) \\ Bronchodilator response}

Baseline lung function was measured in 20 children with recurrent wheeze (age: $4.04 \pm 0.55$ year, height: $101.3 \pm 7.4 \mathrm{~cm}$ ) and 23 healthy children (age: $4.29 \pm 0.51$ year, height: 99.6 $\pm 5.3 \mathrm{~cm}$ ). Three wheezy children were not able to repeat the lung function test after administration of salbutamol. Bronchodilator response in Zrs measured with the multiplefrequency signal is illustrated in figure 8 . There was no significant difference between the groups either at baseline or in their responses to salbutamol. Despite the lack of differences in the conventional FOT variables, $\Delta \mathrm{R}$ and $\mathrm{R}_{\text {meanI }}$ were significantly increased at baseline in the wheezy children compared with the healthy children (table 5). Sixteen of the 20 wheezy children had a baseline $\Delta \mathrm{R}$ higher than the cut-off value defined for airway obstruction in study $\mathrm{I}$, while $\Delta \mathrm{R}$ was below the cut-off in $96 \%$ of the healthy children (22 out of the 23 ). The difference in $\Delta \mathrm{R}$ between the groups disappeared after the administration of salbutamol (figure 9, $\mathrm{p}=0.38$ ).

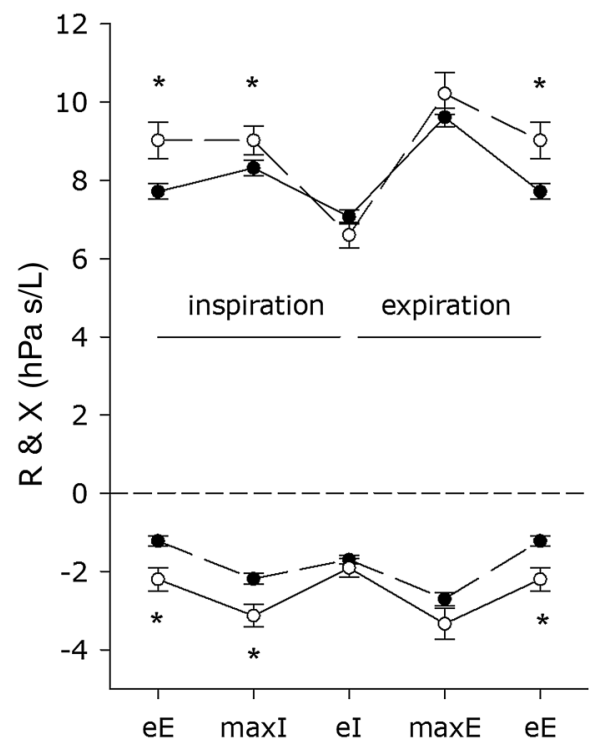

Figure 5 Mean values of resistance ( $R$, top) and reactance ( $X$, bottom) in children with (open circles) and without acute airway obstruction (closed circles) at the end of expiration (eE), maximum inspiratory flow (maxl), end of inspiration (el) and maximum expiratory flow (maxE). Bars represent SEM values; * statistically significant difference between groups.

\section{DISCUSSION}

The results from the present study demonstrate that the change of respiratory resistance during normal breathing is a highly specific and sensitive measure of airway obstruction in young children, whereas the conventional averaged estimates of respiratory resistance fail to discriminate between the wheezing and healthy preschool-age children. Together with the known feasibility of the FOT in young children and the achievable high success rate the extension of this technique to the within-breath analysis of respiratory mechanics has the potential to reveal physiologically and clinically important alterations in airway function.

Respiratory resistance is assumed to reflect airway calibre; therefore, FOT measurements have been employed widely in paediatric studies in various groups of patients with respiratory disease. $^{23-28}$ While some of these studies suggested that, similarly to other methods, such as spirometry ${ }^{5} 7$ and multiple breath washout ${ }^{29} 30$ the FOT was able to distinguish between healthy and diseased subject groups, ${ }^{25} 28{ }^{31-33}$ others raised concerns about the diagnostic value of the Zrs data, especially in young children. ${ }^{23} 24262734$ The controversies surrounding the FOT arise from the diversity of Zrs measures reported from the various studies and also from the wide range of the normal values in the paediatric population for any given age or height. $^{10-13}$ The large variability of the Zrs in healthy preschool-age children can be explained, in part, by the unstable end-expiratory lung volume level and the variable breathing patterns adopted by young children. ${ }^{35}$ In agreement with the body of the literature we did not find a difference between healthy and wheezy children when using conventional mean values of Zrs measures from whole breathing cycles or considering only the inspiratory phase as proposed recently. ${ }^{19} 3236$

Previous investigations suggested that $\mathrm{R}$ measured during spontaneous breathing reflects the overall airway calibre and is also determined by the airflow through the upper airways and larger conducting airways. ${ }^{37}$ In agreement with earlier findings, ${ }^{16-19}$ our within-breath Zrs data demonstrated that $\mathrm{R}$ increases with expiratory flow reaching its peak at the maximum flow that can be related to the vocal cord movements during tidal breathing (ie, during expiration, the glottic aperture narrows and reaches its smallest diameter at midexpiration). ${ }^{20} 21$ It is important to note that, the glottic aperture resumes its original area at the end of expiration in healthy adults. Since there are no data available on vocal cord movements in airway obstruction in children, we cannot exclude the possibility that, contrary to the findings in adults, ${ }^{20} 21$ the relatively narrow glottic aperture during expiration does not completely return to its original size by the time inspiration begins, possibly affecting $\mathrm{R}$ at the end-expiration, and hence $\Delta \mathrm{R}$. Although further investigations are required to localise the airway obstruction (ie, intrapulmonary vs extrapulmonary), our data suggest that independently of the exact location, $\Delta \mathrm{R}$ is a sensitive and specific indicator of the airway obstruction in young children. These findings support our hypothesis that by the identification of the zero-flow resistance points we can minimise the effect of the non-linear, flow-dependent behaviour of the upper airways on R.

Although flow dependence of $\mathrm{R}$ is also significant in inspiration, the mean values of the inspiratory $R$ have been suggested as a surrogate measure of airway resistance. ${ }^{16}$ In the present study, the diagnostic value of $\mathrm{R}_{\text {meanI }}$ was weak, which suggests that flow-dependent contributions to $\mathrm{R}$ during inspiration did not differ between groups. The flow dependence of $\mathrm{R}$, present in both inspiratory and expiratory phases, is primarily related to 

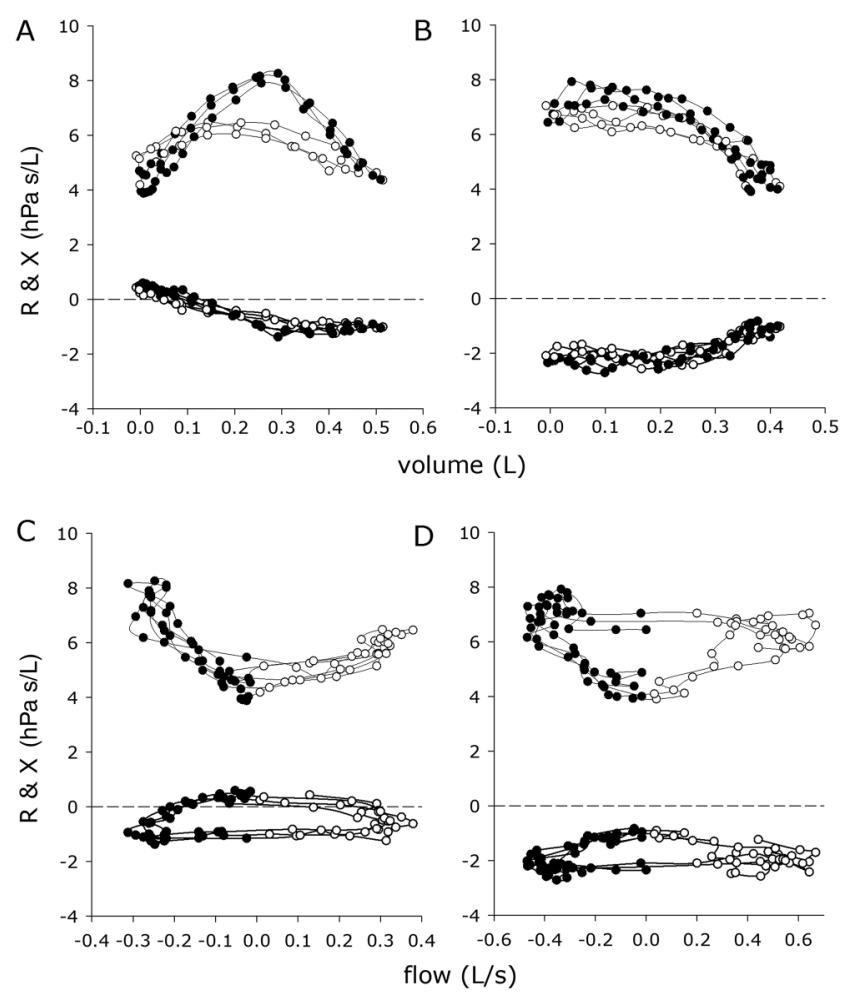

Figure 6 Tidal changes with volume (A and $B$ ) and flow (D and $C)$ in resistance ( $R$, top) and reactance $(X$, bottom) during inspiration (open circles) and expiration (closed circles) in a healthy subject (A and $C$ ) and in a child with acute airway obstruction (B and D).

the breathing pattern and not to the degree of obstruction, and this may exert a masking effect on the assessment of airway calibre. This finding may explain why the average $\mathrm{R}$ obtained with the conventional FOT is poor in separating normal and diseased subject groups. Indeed, significant improvements in sensitivity and specificity were attained in the present study when the influence of flow on $\mathrm{R}$ was eliminated by examining the change in $\mathrm{R}$ between the zero-flow, that is, end-inspiratory and end-expiratory points $(\Delta \mathrm{R})$. The diagnostic power of $\Delta \mathrm{R}$ reported in the present study is much greater than that of any lung function index, including that of the FOT, reported previously in the preschool-age group. ${ }^{27} 33$

The mechanisms by which $\Delta \mathrm{R}$ differs between healthy children and those with acute airway obstruction are likely to be complex, and their clarification needs further investigation. Nevertheless, the fact that the difference in $\mathrm{R}$ at end-expiration between the two groups diminishes during inspiration suggests that the airways of children with acute obstruction demonstrate an increased baseline constrictor tone before inspiration begins (ie, at functional residual capacity) that is reduced by a normal tidal expansion of the lungs but then re-established during expiration. This finding is consistent with the observation in precision-cut human lung slices where the acetylcholine-induced smooth muscle constriction of the individual intraparenchymal airways was reversed with the tidal expansion. ${ }^{38}$ It is also possible that inhomogeneity in the resistance of the distal airways at end-expiration is higher in children with obstruction; this is indicated by both a higher $\mathrm{R}$ and an increase in apparent elasticity of the lungs ${ }^{39} 40$ as reflected by the more negative $\mathrm{X}$ values that also return to a normal level at end-inspiration. The inhomogeneity of peripheral resistance might reach the degree of cyclic closure and reopening of some peripheral lung units, which would also be consistent with the observed changes in $\mathrm{R}$ and $\mathrm{X}$. The coupling of the resistive and elastic parameters during the breathing cycle is also supported by the second highest value of the AUC (0.79) observed in the ROC analysis for $\Delta \mathrm{X}$.

Analysis of $\mathrm{R}$ as a bilinear function of flow and volume has proved useful in characterising the volume dependence before and after methacholine provocation ${ }^{18} 37$ and subsequent bronchodilatation in children with a history of cough or asthma. ${ }^{19}$ In the present study, expiratory flow limitation was present (and the ratio $\mathrm{V}_{\text {maxE }}^{\prime} / \mathrm{V}^{\prime}{ }_{\text {max }}$ reduced) in acute airway obstruction compared with that in healthy children. However, detailed analysis of our data suggests that changes in $\mathrm{R}$ with tidal volume are more specific for airway obstruction than the changes in the flow profile (data are not shown). On the basis of the cut-off value of $\Delta \mathrm{R}$ established in
A

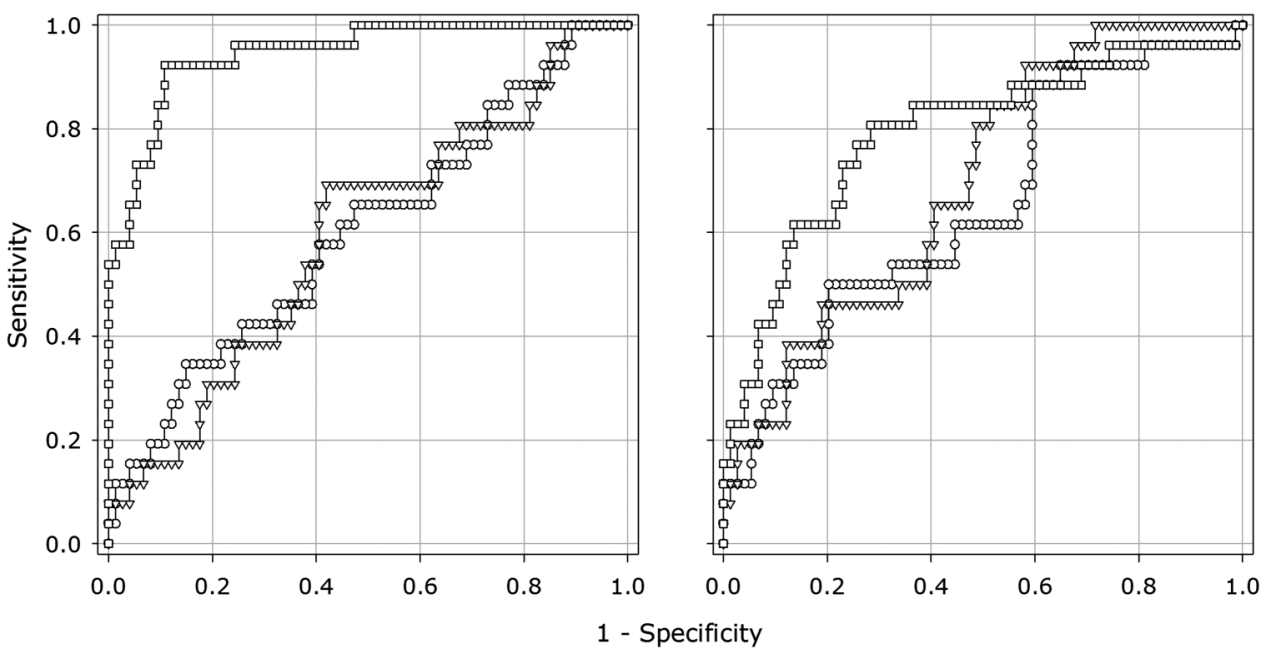

B Figure 7 Receiver operator characteristic curves for within-breath resistance $(A)$ and reactance measures $(B)$. The open squares represent the
difference between the end-expiratory and end-inspiratory resistance $(\Delta R)$ or reactance $(\Delta X)$ values; open circles and triangles indicate the mean values of the resistance and reactance in expiration $\left(R_{\text {meanE, }} X_{\text {meanE }}\right)$ and inspiration $\left(R_{\text {meanl, }}, X_{\text {meanl }}\right)$, respectively. 

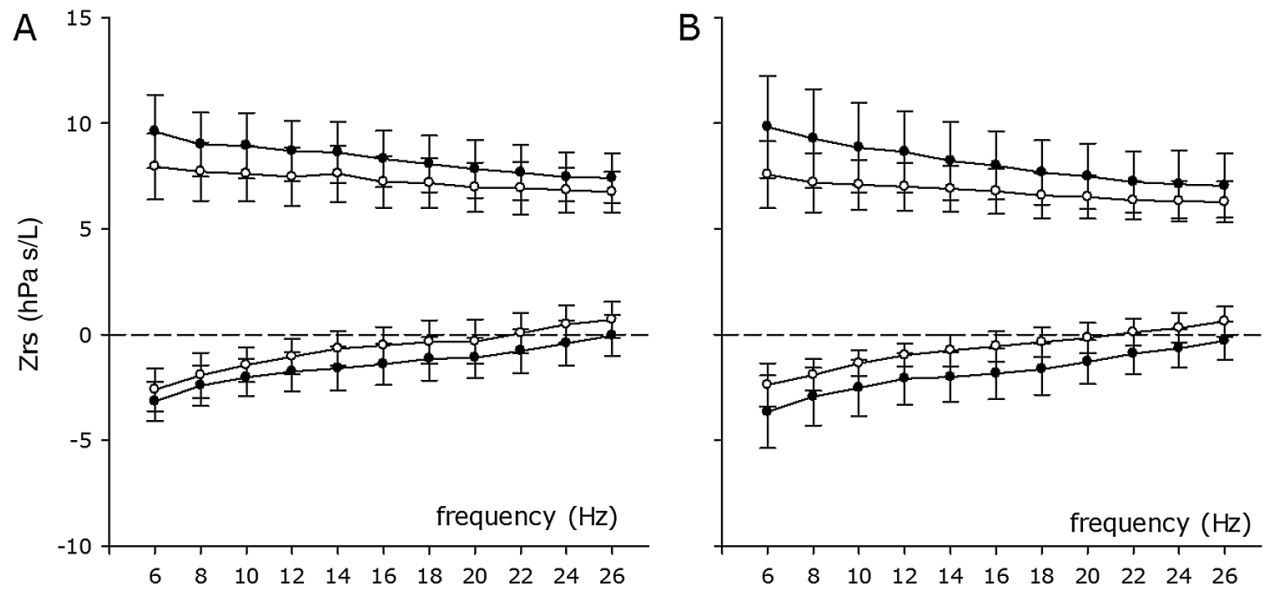

Figure 8 Respiratory impedance (Zrs) between 6 and $26 \mathrm{~Hz}$ in healthy (A) and children with recurrent wheeze (B) before (closed circles) and after administration of salbutamol (open circles). Bars represent SD.

children with acute airway obstruction, $80 \%$ of the children with recurrent wheeze were identified as having airway obstruction in our test population and $96 \%$ of the healthy children were properly classified as not having airway obstruction before the administration of salbutamol. Furthermore, all variables we studied changed in both groups significantly and uniformly in response to salbutamol, whereas $\Delta \mathrm{R}$ only decreased in asthmatics and was thus able to differentiate between the groups. This finding suggests that although these children with well controlled stable asthma exhibit conventional lung function measures apparently very similar to that of the healthy children (this may partly be due to the relatively low contribution of the small airways to the total resistance of the respiratory system), a sensitive technique is able to reveal the alterations in their airway function. Further investigations are needed to establish whether the lack of a high $\Delta \mathrm{R}$ and response to salbutamol in some of our wheezy children reflects a well controlled and/or early stage of disease without ongoing inflammation and airway remodelling, or it is associated with structural alterations of the airway wall that result in a decreased airway distensibility which cannot be eliminated by the administration of bronchodilator agonist.

Since the influences of height and age on $\Delta \mathrm{R}$ and $\Delta \mathrm{X}$ were not significant in the present study, the cut-off values established for children between 3 and 7 years of age can be applied safely to other populations of young children with similar demographics. However, it is important to note that the potential of $\Delta \mathrm{R}$ as a descriptor of airway dynamics in children with paediatric respiratory conditions other than asthma, such as those associated with peripheral abnormalities (cystic fibrosis and interstitial lung disease) needs to be further investigated. Additionally, although the primary aim of this study was the comparison of the within-breath approach with conventional FOT, assessment of agreement with other techniques commonly employed in the preschool age (multiple breath washout, forced spirometry) would be informative. We nevertheless think that the present results document a methodological advance worthy of further investigation in larger and longitudinal studies.

Table 5 Resistance $(R)$ and reactance $(X)$ measures calculated at $6 \mathrm{~Hz}\left(R_{6}\right.$ and $\left.X_{6}\right)$, separately for expiration $\left(R_{\text {meanE }}\right.$ and $\left.X_{\text {meanE }}\right)$, inspiration $\left(R_{\text {meanl }}\right.$ and $\left.X_{\text {meanl }}\right)$ and the volume dependence $(\Delta R$ and $\Delta X)$ in two groups of children presalbutamol and postsalbutamol (study II)

\begin{tabular}{|c|c|c|c|c|c|c|c|}
\hline \multirow[b]{2}{*}{ Lung function variables } & \multicolumn{3}{|c|}{ Healthy $(n=23)$} & \multicolumn{3}{|c|}{ Recurrent wheeze $(n=17)$} & \multirow[b]{2}{*}{ p Valuet } \\
\hline & Pre & Post & p Value* & Pre & Post & p Value* & \\
\hline Tidal volume (mL) & $244 \pm 193$ & $220 \pm 183$ & 0.29 & $211 \pm 156$ & $209 \pm 144$ & 0.12 & 0.151 \\
\hline $\mathrm{F}_{\mathrm{br}}$ (breath/min) & $27 \pm 4$ & $26 \pm 4$ & 0.41 & $25 \pm 5$ & $26 \pm 4$ & 0.25 & 0.331 \\
\hline $\mathrm{T}_{\mathrm{E}} / \mathrm{T}_{\text {tot }}$ & $0.54 \pm 0.04$ & $0.55 \pm 0.05$ & 0.19 & $0.58 \pm 0.04$ & $0.56 \pm 0.04$ & 0.14 & 0.186 \\
\hline $\mathrm{R}_{6}(\mathrm{hPa} s / \mathrm{L})$ & $9.61 \pm 1.74$ & $7.95 \pm 1.56$ & $<0.001 \ddagger$ & $9.83 \pm 2.41$ & $7.57 \pm 1.58$ & $<0.001 \ddagger$ & 0.398 \\
\hline $\mathrm{R}_{\text {meanE }}(\mathrm{hPa} \mathrm{s} / \mathrm{L}$ ) & $9.25 \pm 1.28$ & $7.96 \pm 1.84$ & $<0.001 \ddagger$ & $9.27 \pm 2.53$ & $6.79 \pm 1.23$ & $<0.001 \ddagger$ & 0.054 \\
\hline $\mathrm{R}_{\text {meanl }}(\mathrm{hPa} \mathrm{s} / \mathrm{L})$ & $8.32 \pm 1.02$ & $7.06 \pm 1.78$ & $<0.001 \ddagger$ & $8.56 \pm 2.00$ & $6.00 \pm 1.06$ & $<0.001 \ddagger$ & $0.023 \ddagger$ \\
\hline $\mathrm{X}_{6}(\mathrm{hPa} \mathrm{s} / \mathrm{L})$ & $-3.16 \pm 0.93$ & $-2.61 \pm 1.01$ & $<0.001 \ddagger$ & $-3.65 \pm 1.72$ & $-2.38 \pm 1.02$ & $<0.001 \ddagger$ & 0.107 \\
\hline $\mathrm{X}_{\text {meanE }}(\mathrm{hPa} \mathrm{s} / \mathrm{L})$ & $-2.27 \pm 1.14$ & $-1.36 \pm 0.91$ & $<0.001 \ddagger$ & $-2.28 \pm 1.57$ & $-0.95 \pm 0.91$ & $<0.001 \ddagger$ & 0.237 \\
\hline $\mathrm{X}_{\text {meanl }}(\mathrm{hPa} \mathrm{s} / \mathrm{L})$ & $-2.08 \pm 0.88$ & $-1.16 \pm 0.73$ & $<0.001 \ddagger$ & $-2.21 \pm 1.08$ & $-0.91 \pm 0.61$ & $<0.001 \ddagger$ & 0.178 \\
\hline$\Delta \mathrm{R}(\mathrm{hPa} s / \mathrm{L})$ & $0.67 \pm 0.58$ & $0.26 \pm 0.82$ & 0.065 & $2.00 \pm 1.21$ & $0.52 \pm 0.46$ & $<0.001 \ddagger$ & $<0.001 \ddagger$ \\
\hline$\Delta \mathrm{X}(\mathrm{hPa} \mathrm{s} / \mathrm{L})$ & $-0.36 \pm 0.51$ & $-0.69 \pm 0.38$ & $0.002 \ddagger$ & $-0.08 \pm 1.02$ & $-0.65 \pm 0.51$ & $0.02 \ddagger$ & 0.089 \\
\hline
\end{tabular}



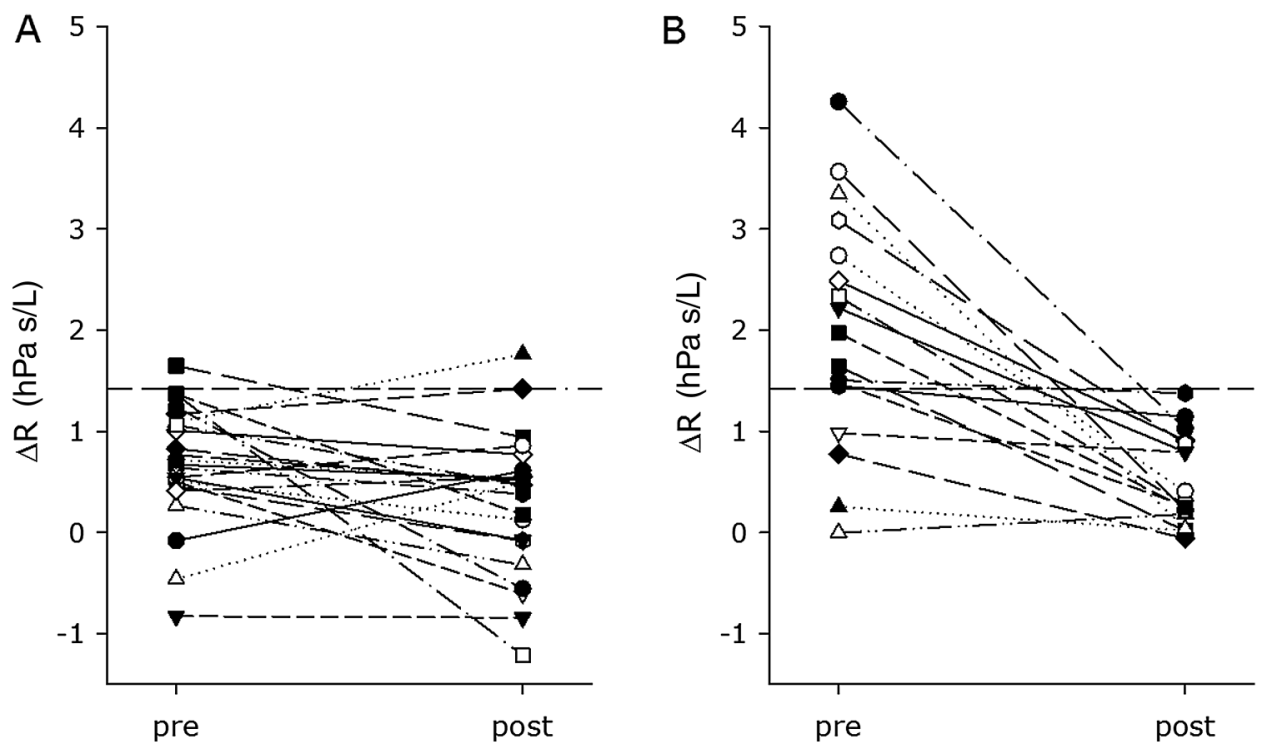

Figure 9 Individual changes in volume dependence of resistance $(\Delta R)$ preadministration and postadministration of salbutamol. Symbols and lines represent data in healthy children $(A)$ and children with recurrent wheeze (B). The horizontal dashed line shows the cut-off value of $\Delta R$ for airway obstruction (1.42 hPa s/L).

In conclusion, the assessment of the tidal and flow-independent changes in forced oscillatory resistance in the present study has resulted in a significant improvement in the sensitivity and specificity attained previously with the FOT and other lung function tests in the differentiation between healthy preschool-age children and those with acute bronchial obstruction. The cut-off value of $\Delta \mathrm{R}$ used in a test population properly separated wheezy and healthy children. Our results demonstrate the potential of the within-breath approach of the FOT in the assessment of lung disease in individual patients.

\section{Author affiliations \\ ${ }^{1}$ Children's Lung, Environment and Asthma Research Team, University of Queensland, Brisbane, Queensland, Australia \\ ${ }^{2}$ Child Health Research Centre, University of Queensland, Brisbane, Queensland, Australia \\ ${ }^{3}$ Department of Medical Physics and Informatics, University of Szeged, Szeged, Hungary \\ ${ }^{4}$ Department of Pulmonology, University of Szeged, Szeged, Hungary \\ ${ }^{5}$ Department of Technical Informatics, University of Szeged, Szeged, Hungary}

Acknowledgements The authors wish to thank all the staff members of the Respiratory Department and Respiratory Function Laboratories within the Royal Children's Hospital, Brisbane for their support with participant recruitment and testing throughout the study. We would also like to thank the children and their families for their time and help to participate in the present studies.

Contributors DC, CS, ZH and PDS conceived the study and designed the measurement principle. CS, DC, KT, AK and AC recruited patients and collected data. DC, ZH, GM, BR and ZG designed the methods of measurement and data processing. DC, CS and RSW processed the recordings and analysed the data. DC, $\mathrm{ZH}$ and PDS drafted the manuscript. All authors have seen and approved the submitted manuscript.

Funding The study has been supported by the National Health and Medical Research Council of Australia (\#1002035 and \#1078600), the Office of Health and Medical Research, Government of Queensland (\#50133) and the Royal Children's Hospital Foundation, Brisbane, Queensland, Australia (\#50005), Hungarian Scientific Research Fund (\#105403), European Respiratory Society Clinical Research Collaboration Award ERS-CRC-2013-02.

Competing interests None declared.

Ethics approval Children's Health Services Human Research Ethics Committee, Brisbane, Australia.

Provenance and peer review Not commissioned; externally peer reviewed.

\section{REFERENCES}

1 Beydon N, Davis SD, Lombardi E, et al. An official American Thoracic Society/ European Respiratory Society statement: pulmonary function testing in preschool children. Am J Respir Crit Care Med 2007;175:1304-45.

2 Ducharme FM, Davis GM. Measurement of respiratory resistance in the emergency department: feasibility in young children with acute asthma. Chest 1997;111:1519-25.

3 Rosenfeld M, Allen J, Arets BH, et al. An official American Thoracic Society workshop report: optimal lung function tests for monitoring cystic fibrosis, bronchopulmonary dysplasia, and recurrent wheezing in children less than 6 years of age. Ann Am Thorac Soc 2013;10:S1-11.

4 Nath JB, Hsia RY. Children's emergency department use for asthma, 2001-2010. Acad Pediatr 2015;15:225-30.

5 Dundas I, Chan EY, Bridge PD, et al. Diagnostic accuracy of bronchodilator responsiveness in wheezy children. Thorax 2005;60:13-16.

6 Kampschmidt JC, Brooks EG, Cherry DC, et al. Feasibility of spirometry testing in preschool children. Pediatr Pulmonol 2016;51:258-66.

7 Pijnenburg MW, Baraldi E, Brand PL, et al. Monitoring asthma in children. Eur Respir J 2015;45:906-25.

8 Bates JH, Irvin CG, Farré R, et al. Oscillation mechanics of the respiratory system. Compr Physiol 2011;1:1233-72.

9 Marchal F, Hall GL. Forced oscillation technique. In: Frey U, Merkus PJFM, eds. Paediatric Lung Function. European Respiratory Monograph, 2010:121-36.

10 Ducharme FM, Davis GM, Ducharme GR. Pediatric reference values for respiratory resistance measured by forced oscillation. Chest 1998;113:1322-8.

11 Klug B, Bisgaard $\mathrm{H}$. Specific airway resistance, interrupter resistance, and respiratory impedance in healthy children aged 2-7 years. Pediatr Pulmonol 1998;25:322-31.

12 Calogero C, Simpson SJ, Lombardi E, et al. Respiratory impedance and bronchodilator responsiveness in healthy children aged 2-13 years. Pediatr Pulmonol 2013;48:707-15

13 Hantos Z, Daróczy B, Gyurkovits K. Total respiratory impedance in healthy children. Pediatr Pulmonol 1985;1:91-8.

14 Lándsér FJ, Nagles J, Demedts $M$, et al. A new method to determine frequency characteristics of the respiratory system. J App/ Physiol 1976;41:101-6.

15 Michaelson ED, Grassman ED, Peters WR. Pulmonary mechanics by spectral analysis of forced random noise. J Clin Invest 1975;56:1210-30.

16 Davidson RN, Greig CA, Hussain A, et al. Within-breath changes of airway calibre in patients with airflow obstruction by continuous measurement of respiratory impedance. Br J Dis Chest 1986;80:335-52.

17 Peslin R, Ying Y, Gallina C, et al. Within-breath variations of forced oscillation resistance in healthy subjects. Eur Respir J 1992;5:86-92.

18 Marchal F, Loos N, Monin P, et al. Methacholine-induced volume dependence of respiratory resistance in preschool children. Eur Respir J 1999;14:1167-74.

19 Marchal F, Schweitzer C, Moreau-Colson C. Respiratory impedance response to a deep inhalation in children with history of cough or asthma. Pediatr Pulmonol 2002:33:411-18.

20 England SJ, Bartlett D Jr, Daubenspeck JA. Influence of human vocal cord movements on airflow and resistance during eupnea. J Appl Physiol Respir Environ Exerc Physiol 1982;52:773-9. 
21 England SJ, Ho V, Zamel N. Laryngeal constriction in normal humans during experimentally induced bronchoconstriction. J Appl Physiol (1985) 1985;58:352-6.

22 Hantos Z, Czövek D, Gyurkovits Z, et al. Assessment of respiratory mechanics with forced oscillations in healthy newborns. Pediatr Pulmonol 2015;50:344-52.

23 Solymar L, Aronsson PH, Sixt R. The forced oscillation technique in children with respiratory disease. Pediatr Pulmonol 1985;1:256-61.

24 Nielsen KG, Pressler T, Klug B, et al. Serial lung function and responsiveness in cystic fibrosis during early childhood. Am J Respir Crit Care Med 2004;169:1209-16.

25 Udomittipong K, Sly PD, Patterson HJ, et al. Forced oscillations in the clinical setting in young children with neonatal lung disease. Eur Respir J 2008:31:1292-9.

26 Harrison J, Gibson AM, Johnson K, et al. Lung function in preschool children with a history of wheezing measured by forced oscillation and plethysmographic specific airway resistance. Pediatr Pulmonol 2010;45:1049-56.

27 Cuijpers CE, Wesseling GJ, Kessels AG, et al. Low diagnostic value of respiratory impedance measurements in children. Eur Respir $J$ 1997:10:88-93.

28 Lall CA, Cheng N, Hernandez $\mathrm{P}$, et al. Airway resistance variability and response to bronchodilator in children with asthma. Eur Respir J 2007;30:260-8.

29 Sonnappa S, Bastardo CM, Wade A, et al. Symptom-pattern phenotype and pulmonary function in preschool wheezers. J Allergy Clin Immunol 2010;126:519-26.e1-7

30 Macleod KA, Horsley AR, Bell NJ, et al. Ventilation heterogeneity in children with well controlled asthma with normal spirometry indicates residual airways disease. Thorax 2009;64:33-7.

31 Nielsen KG, Bisgaard H. Discriminative capacity of bronchodilator response measured with three different lung function techniques in asthmatic and healthy children aged 2 to 5 years. Am J Respir Crit Care Med 2001; 164:554-9.

32 Vu LT, Demoulin B, Nguyen MT, et al. Respiratory impedance and response to salbutamol in asthmatic Vietnamese children. Pediatr Pulmonol 2010; 45:380-6.

33 Delacourt $\mathrm{C}$, Lorino $\mathrm{H}$, Herve-Guillot $\mathrm{M}$, et al. Use of the forced oscillation technique to assess airway obstruction and reversibility in children. Am J Respir Crit Care Med 2000;161:730-6.

34 Thamrin C, Gangell CL, Udomittipong K, et al. Assessment of bronchodilator responsiveness in preschool children using forced oscillations. Thorax 2007:62:814-19.

35 van der Ent CK, Brackel HJ, van der Laag J, et al. Tidal breathing analysis as a measure of airway obstruction in children three years of age and older. Am J Respir Crit Care Med 1996;153:1253-8.

36 Schweitzer C, Moreau-Colson C, Marchal F. Respiratory impedance response to a deep inhalation in asthmatic children with spontaneous airway obstruction. Eur Respir J 2002;19:1020-5.

37 Loos N, Peslin R, Marchal F. Respiratory and upper airways impedance responses to methacholine inhalation in spontaneously breathing cats. Eur Respir J 2000;15:1001-8

38 Lavoie $T L$, Krishnan R, Siegel HR, et al. Dilatation of the constricted human airway by tidal expansion of lung parenchyma. Am J Respir Crit Care Med 2012;186:225-32.

39 Grimby G, Takishima T, Graham W, et al. Frequency dependence of flow resistance in patients with obstructive lung disease. J Clin Invest 1968;47:1455-65.

40 Lutchen KR, Gillis H. Relationship between heterogeneous changes in airway morphometry and lung resistance and elastance. J Appl Physiol (1985) 1997;83:1192-201. 